\title{
Staged treatment of central and peripheral lesions in chronic thromboembolic pulmonary hypertension
}

\author{
Grzegorz Kopeć ${ }^{1}$, Jakub Stępniewski ${ }^{1}$, Marcin Waligóra', \\ Marcin Kurzyna ${ }^{2}$, Andrzej Biederman ${ }^{3}$, Piotr Podolec ${ }^{1}$ \\ 1 Department of Cardiac and Vascular Disease, Jagiellonian University Medical College, John Paul II Hospital, Kraków, Poland \\ 2 Department of Pulmonary Circulation and Thromboembolic Diseases, Medical Centre of Postgraduate Education, European Health Centre Otwock, Otwock, Poland \\ 3 Department of Cardiac Surgery, Allenort Hospital, Warsaw, Poland
}

Correspondence to:

Grzegorz Kopeć, MD, PhD, Klinika Chorób Serca i Naczyń, Uniwersytet Jagielloński, Collegium Medicum, Krakowski Szpital Specjalistyczny im. Jana Pawła Il, ul. Prądnicka 80, 31-202 Kraków, Poland, phone: +48 1261433 99, e-mail: grzegorzkrakow1@gmail.com Received: November 21, 2015. Revision accepted: December 21, 2015. Conflict of interests: none declared. Pol Arch Med Wewn. 2016; 126 (1-2): $97-99$ Copyright by Medycyna Praktyczna, Kraków 2016
Pulmonary endarterectomy (PEA) is a method of choice for the treatment of chronic thromboembolic pulmonary hypertension (CTEPH). ${ }^{1,2}$ However, in a substantial number of patients, organized thrombi are located peripherally and are not easily accessible during PEA. These patients are at risk for persistent pulmonary hypertension (PH) after PEA. We present a case of a patient with central and peripheral organized thrombi, in whom a combination of PEA and subsequent percutaneous balloon pulmonary angioplasty (BPA) ${ }^{3-5}$ eventually led to near-normalization of pulmonary hemodynamics. Despite possible serious complications of PEA (reperfusion lung injury, neurological complications, persistent $\mathrm{PH}$, or death) and BPA (reperfusion lung injury, vessel rupture, or death), the benefits clearly outweigh the risk of these procedures. ${ }^{1-3}$

A 65-year-old woman with a history of acute pulmonary embolism was referred to a $\mathrm{PH}$ center due to chronic dyspnea (World Health Organization functional class [WHO-FC] IV) and typical echocardiographic sings of precapillary $\mathrm{PH}$. Computed tomography pulmonary angiography showed organized thrombi in the segmental and subsegmental arteries of both lungs. Right heart catheterization (RHC) and conventional left and right pulmonary angiography confirmed the diagnosis of CTEPH. Mean pulmonary artery pressure (mPAP) was $52 \mathrm{mmHg}$; pulmonary vascular resistance (PVR), 10.3 Wood units (WU); right atrial pressure (RAP), $10 \mathrm{mmHg}$; and cardiac index (CI), $2.1 \mathrm{l} / \mathrm{min} / \mathrm{m}^{2}$. Pulmonary angiography (FIGURES $1 \mathrm{~A}$ and $1 \mathrm{~B}$ ) revealed numerous organized thrombi in the segmental and subsegmental arteries of both lungs, including total occlusions, webs and bends, and abrupt narrowings. The patient was referred for PEA, which was performed without major complications. During follow-up, the patient still complained of exertional dyspnea (WHO-FC III). Lung scintigraphy revealed multiple mismatched segmental perfusion defects in both lungs. RHC performed 9 months after $\mathrm{PEA}$ revealed persistent $\mathrm{PH}$ with an $\mathrm{mPAP}$ of $38 \mathrm{mmHg}$, PVR of $9.7 \mathrm{WU}, \mathrm{CI}$ of $1.6 \mathrm{l} / \mathrm{min} / \mathrm{m}^{2}$, and RAP of $17 \mathrm{mmHg}$. Pulmonary angiography (FIGURES 1C and 1D) showed incomplete revascularization of pulmonary vasculature. Since riociguat, the only approved drug for persistent CTEPH, was not available at that time, the patient was directly referred for BPA. Between January and June 2015, she underwent 5 sessions of BPA with a total number of 32 lesions treated, including recanalization of 3 total occlusions. Three sessions were devoted to treat 14 lesions including 1 total occlusion in RPA branches and 2 sessions to dilate 15 lesions and to recanalize 2 occlusions in left pulmonary artery branches. Catheter balloons with diameters ranging between 2.0 and $7.0 \mathrm{~mm}$ were used. An example of a BPA procedure in the upper lobe anterior (A3) branch of the left pulmonary artery is shown in FIGURE $1 \mathrm{E}$ and $1 \mathrm{~F}$. No complications occurred during or after any of the BPA sessions. BPA led to a decrease of mPAP to 24 $\mathrm{mmHg}$, PVR to $4.1 \mathrm{WU}$, mean RAP to $4 \mathrm{mmHg}$, and an increase of $\mathrm{CI}$ to $2.8 \mathrm{l} / \mathrm{min} / \mathrm{m}^{2}$. It also resulted in a significant clinical improvement with an increase of 6-minute walking distance from $200 \mathrm{~m}$ to $340 \mathrm{~m}$ and a decrease of the WHO-FC from III to II. These effects were still present 3 months after the last BPA session.

We conclude that a combination of PEA with subsequent BPA can be a therapeutic option for patients with CTEPH and a coexistence of central and peripheral lesions. 

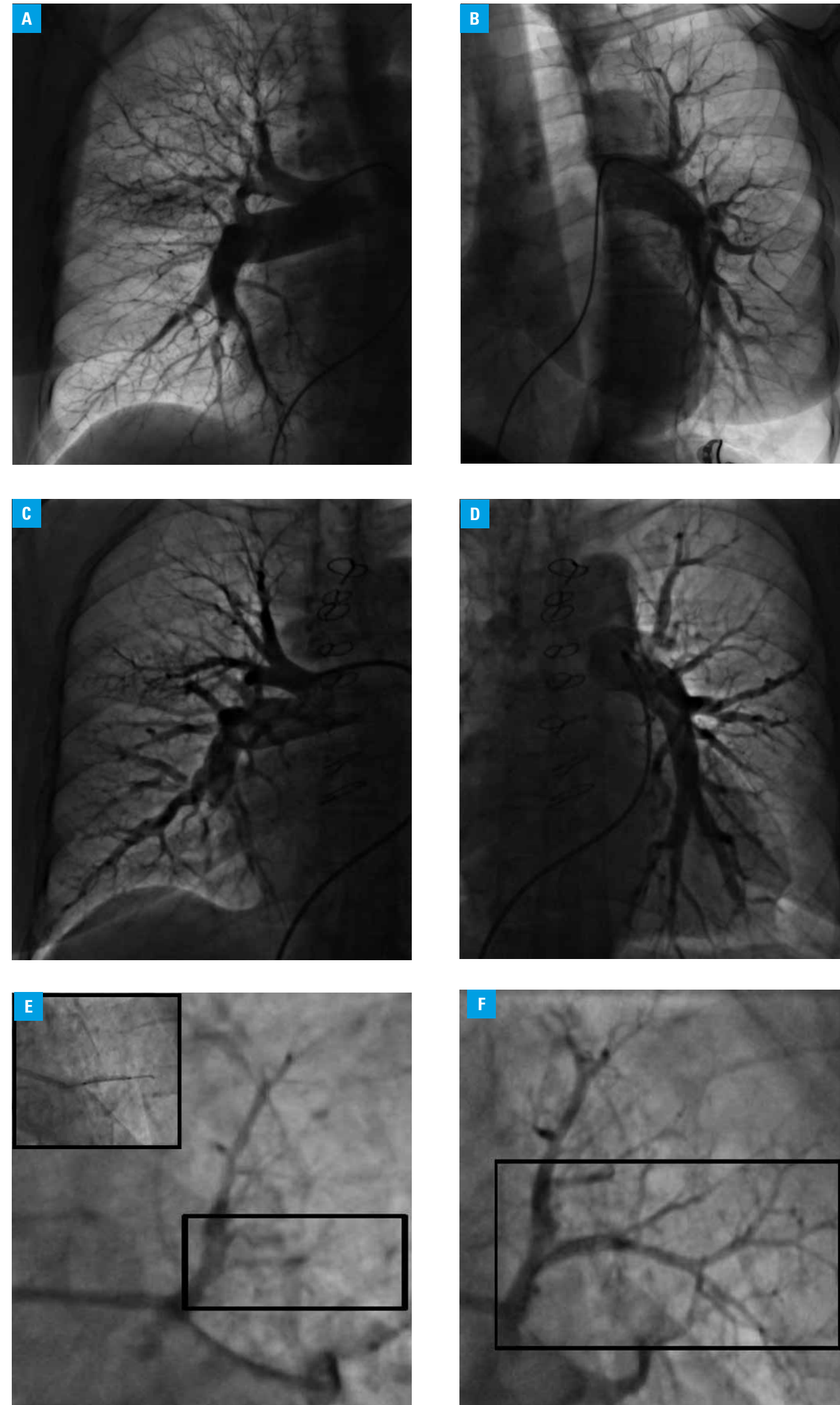

FIGURE 1 Pulmonary angiography of the right (A, B) and left (C, D) pulmonary arteries before $(A, C)$ and after (B, D) pulmonary endarterectomy shows incomplete revascularization of pulmonary vasculature. Balloon pulmonary angioplasty of a totally occluded upper lobe anterior (A3) branch of the left pulmonary artery with catheter balloons, $1.25 \mathrm{~mm}$ and $2.0 \mathrm{~mm}$ (frame in panel E), leading to peripheral flow restoration (frame in panel F). 


\section{REFERENCES}

1 Kurzyna M, Darocha S, Koteja A, et al. Balloon pulmonary angioplasty for chronic thromboembolic pulmonary hypertension. Postepy Kardiol Interwencyjnej. 2015; 11: 1-4.

2 Lang IM, Madani M. Update on chronic thromboembolic pulmonary hypertension. Circulation. 2014; 130: 508-518.

3 Mizoguchi H, Ogawa A, Munemasa M, et al. Refined balloon pulmonary angioplasty for inoperable patients with chronic thromboembolic pulmonary hypertension. Circ Cardiovasc Interv. 2012; 5: 748-755.

4 Kopeć G, Waligóra M, Stępniewski J, et al. In vivo characterization of changes in composition of organized thrombus in patient with chronic thromboembolic pulmonary hypertension treated with balloon pulmonary angioplasty. Int J Cardiol. 2015; 186: 279-281.

5 Roik M, Wretowski D, tabyk A, et al. Optical coherence tomography of inoperable chronic thromboembolic pulmonary hypertension treated with refined balloon pulmonary angioplasty. Pol Arch Med Wewn. 2014; 124 $742-743$ 